\title{
Mídia e poder: o que esconde o brilho luminoso da tela da TV?
}

\section{RESUMO}

A televisão é a versão moderna da praça pública na qual a sociedade se encontrava na Grécia Antiga. A tela luminosa da TV representa a Ágora. Mas não se trata de uma simples substituição. As cores, formas, imagens, palavras, sons e silêncios, através da televisão, ajudam a construir o imaginário social. A TV é hoje o espaço público onde a vida acontece. E, através dessa lente de observação, se tentará avaliar a influência política da televisão no Brasil contemporâneo.

\section{PALAVRAS-CHAVE}

- televisão

- mídia

- poder

\section{ABSTRACT}

Television is the modern version of public square in which society was located in Ancient Greece. TV's luminous screen represents Agora. However, it is not a simple substitution. Colors, shapes, images, words, sounds and silences, through the television, act in order to build the social imaginary. TV is today the public space where life happens. In addition, through this lens of observation, it will try to evaluate the political influence of television in contemporaneous Brazil.

\section{KEY WORDS}

- television

- media

- power

\section{Veja a seguir: introdução}

0 que aparece diante da tela da TV todos nós sabemos. É só olhar e, cada um à sua maneira, interpretar o que significam as cores, formas, imagens, palavras, sons e silêncios que se sucedem de forma constante e interminável na tela luminosa que atrai a atenção. A tela que, para milhões de pessoas é a única janela para o mundo, põe o mundo dentro da nossa casa. Ali é possível saber de tudo o que aconteceu no planeta mesmo que para o telespectador aquele mundo de informações não tenha a menor importância e não signifique absolutamente nada. Alguém já dizia: a televisão mostra tudo o que acontece na China, mas não diz nada do que ocorre na esquina. É uma verdade parcial. Se o que ocorre na esquina estiver sendo captado por uma câmera de TV que, naturalmente, pertença a uma rede de emissoras de um grande conglomerado de Mídia, bem aí sim, vamos poder ver na TV o que acontece na nossa esquina. E o mesmo vai ser visto também lá na China. Esse texto inicial é uma provocação. Seja na esquina ou na China, o que vemos na TV todos nós sabemos: é só olhar para a tela luminosa. Mas e o que não aparece na TV? E o que ela deixa de mostrar? Formulando melhor a questão: o que esconde a tela luminosa da TV? É o que tentaremos desvendar nas linhas que virão a seguir.

\section{Vinheta de abertura: a identidade}

Se esse fosse um papel digital com o texto de abertura de um telejornal ou outro programa jornalístico de televisão aqui estaríamos escutando um som instrumental com sentido de convocação, como as trombetas que no passado chamavam as pessoas para uma reunião em praça pública onde ouviriam mensagens do Rei ou notícias vindas de longe através dos relatos de mensageiros. O som é o fundo musical para uma sucessiva seqüência de imagens e efeitos visuais, como o planeta girando, como a Globo faz no Jornal Nacional, ou um satélite em órbita em torno da terra, como mostra a vinheta de abertura do Jornal da Band. A intenção de todos os telejornais é a mesma: como a sirene de uma fábrica que chama os operários para o trabalho, o propósito de vinheta de abertura de um telejornal é convocar o público telespectador para sentar-se diante da tela luminosa que o mundo vai entrar na sua sala a partir daquele momento.

A vinheta tem um tom convocatório. No rádio seria chamada de cortina musical. Na verdade, além de chamar o público para as notícias que estão chegando, o propósito é o de dar uma identidade ao

Flávio A. C. Porcello FABICO/UFRGS 
produto que será exibido. Se o gênero for na área da dramaturgia, e a telenovela tiver uma temática mais suave, na linha humorística, por certo virão desenhos, animações gráficas multicoloridas e um fundo musical em tons bastante irreverentes. Se a temática for séria, a composição visual será em tons sóbrios e a música mais pesada. $\mathrm{O}$ jogo de cores utilizado para compor uma imagem ou uma seqüência de imagens na TV sempre é bem estudado. Farina (1990, p. 24) observa que "a percepção humana é um conjunto coordenado de impressões e não um grupo de sensações isoladas: uma parede vermelha pode 'avançar', uma parede azul clara parece 'afastar-se' e uma parede amarela 'desaparece' quando a olhamos". Ele analisa a relação das pessoas com as cores que as cercam:

Podemos dizer que vivemos numa iconosfera, na qual o indivíduo penetra desde que nasce. Afirma-se que um homem passa por ano mais de mil horas diante de imagens eletrônicas (fotografia, cinema, Internet, TV). Isso tende a aumentar com a utilização de novos recursos propiciados pela tecnologia. É evidente que, na força comunicativa da imagem, o que predomina é o impacto exercido pela cor. Nem a captação instantânea da forma do objeto pode produzir o impacto emocional que nos é a todo momento proporcionado pela cor (FARINA, 1990, p. 25).

Analistas e profissionais que utilizam a cor em suas atividades cotidianas, como quem atua em TV, sabem que a cor vermelha tem uma representação estática, a cor amarela significa expansão e a cor azul significa vazio. O azul é considerado cor fria, que traz boas sensações. A vermelha é considerada cor quente, que dá sensações intensas. O azul é considerado a cor da TV. Fundos em estúdio, bancadas de telejornais e vinhetas de programas jornalísticos, em todo o mundo, adotam prioritariamente a cor azul em sua identidade visual. Farina (1996, p. 105) estabelece também uma graduação de cores e suas correspondentes sensações nas pessoas:

- Vermelho (de um a dez anos) crianças efervecentes e espontâneas;

- Laranja (de dez a vinte anos) jovens excitados e imaginativos;

- Amarelo (de vinte a trinta anos) pessoas com força e potência;

- Verde (de trinta a quarenta anos) adultos já perdendo o fôlego juvenil;

- Azul (de quarenta a cinqüenta anos) idade que valoriza a experiência e a crítica;

- Lilás (de cinqüenta a sessenta anos) prevalecem o juízo, a lei e a ordem;

- Roxa (de sessenta em diante) valorização do saber e da paciência.
Quem observar a relação entre programas de TV e o público a qual se destinam verá a perfeita sincronia de cores com idades. Programas infantis são explosões de cores e programas destinados às pessoas maduras utilizam cores mais suaves em tons azul, rosa, lilás e roxa. Com os sons é a mesma coisa. Muito barulho para os jovens, sons mais suaves para os velhos.

\section{Escalada de notícias: as manchetes}

Escalar - está em todos os dicionários - é um verbo transitivo que significa subir, avançar para cima, como fazem os alpinistas quando enfrentam desafios de todo o gênero ao tentar escalar montanhas geladas. Em TV a escalada é a seqüência dos principais assuntos que serão apresentados naquela edição. Se quisermos comparar, seria como a capa do jornal, onde estão impressas as principais manchetes do dia. As manchetes estão na capa, o detalhamento das notícias vem dentro do jornal. Na TV é a mesma coisa. A escalada anuncia o que o telejornal vai mostrar. Como TV é imagem em movimento, uma vantagem a favor do telejornal é que a escalada pode ser ilustrada com a seqüência de cenas em movimento. É como se a foto da capa do jornal ganhasse vida e se movimentasse. É um recurso muito utilizado pelos editores de um telejornal para antecipar, ali na escalada ou capa do telejornal, a imagem forte que será mostrada a seguir.

\section{Bloco de notícias: referencial teórico}

"Boa noite: Você vai ver agora o que foi notícia no mundo hoje". Com essa frase ou outra parecida, variando um pouco nos termos ou na entonação de voz dos âncoras, invariavelmente os telejornais começam assim. E aí se sucedem as noticias do dia no Brasil e no mundo concentradas em cerca de 40 minutos. As notícias nos telejornais brasileiros obedecem ao padrão importado do telejornalismo norte-americano. O âncora lê no teleprompter (TP) a 'cabeça' que é uma introdução ao assunto e em seguida começa a matéria (VT) feita pelo repórter. As matérias seguem também o padrão internacional: voz do repórter sobre imagens que tratam do assunto reportado (off), repórter aparecendo na tela em plano americano (stand up ou passagem) e entrevistas com pessoas ligadas ao assunto tratado (sonoras). As matérias duram de um minuto e meio a dois minutos. Se a entrada do repórter não for gravada como a descrita acima, mas 'ao vivo', o procedimento varia um pouco. $\mathrm{O}$ âncora chama, o repórter está posicionado diante da câmera com microfone na mão e começa seu relato que vai durar cerca de 40 segundos sempre enquadrado no chamado 'plano americano' (da cintura para cima). A deixa final para voltar ao estúdio é: "fulano de tal, ao vivo de tal lugar para o jornal tal".

Pronto. Essa é a fórmula que todas as noites mate- 
rializa as notícias do dia na tela da TV. E assim o mundo entra na casa de todos nós. Mas o que foi descrito até agora não traz nenhuma novidade para quem atua em televisão, para quem ensina televisão e mesmo para quem aprende televisão. Nas primeiras aulas de TV nos cursos de jornalismo essa fórmula, antiga e banal, é ensinada. É o modelo que funciona há décadas e que tão cedo não deixará de continuar funcionando. Afinal, os repórteres nos contam seus relatos em forma de histórias e os entrevistados são personagens dessas histórias, cada um cumprindo o papel que lhe foi destinado. Mas o propósito do presente artigo é avançar. A intenção não é relatar o que a TV mostra e nem como mostra. Isso todos sabemos, basta assistir ao telejornal de todas as noites. O propósito é ir mais fundo. É tentar desvendar o que a TV não mostra. Ou, mais ainda: porque ela mostra o que na maior parte das vezes nós já sabemos para deixar de mostrar o que deveríamos saber? Afinal, como propõe o presente artigo: O que se esconde por trás do brilho luminoso da tela da TV?

\section{A TV mostra ou esconde? - análise dos dados}

É importante começarmos a tentar responder essa pergunta com a reflexão proposta por um autor que já é considerado clássico nos estudos de televisão. Pierre Bourdieu, em "Sobre a Televisão", que traz o resumo de duas aulas por ele apresentadas no Collège de France, diz:

Uma parte da ação simbólica da televisão, no plano das informações, por exemplo, consiste em atrair a atenção para fatos que são de natureza a interessar todo mundo, dos quais se pode dizer que são omnibus - isto é, para todos. Os fatos-ônibus são fatos que, como se diz, não devem chocar ninguém, que não envolvem disputa, que não dividem, que formam consenso, que interessam a todo mundo, mas de um modo tal que não tocam em nada de importante (BOURDIEU, 1996, p. 23).

\section{E complementa:}

Ora, o tempo é algo extremamente raro na televisão. E se minutos tão preciosos são empregados para dizer coisas tão fúteis, é que essas coisas tão fúteis são de fato muito importantes na medida em que ocultam coisas preciosas (BOURDIEU, 1996, p. 23).

Aí está contida uma grande verdade. Não seria ético e nem justo com quem trabalha em televisão afirmar que tudo é armado, que existe uma teoria da conspiração para esconder a verdade e iludir as massas desviando sua atenção do que interessa para o que não tem importância. Não é isso. O que existe é uma intenção dos operadores de TV em ganhar a atenção do público, evitando que ele perca o interesse para o assunto e mude de canal. Há quem pense, e muita gente que produz telejornalismo pensa assim, que ao chegar em casa à noite a pessoa que trabalhou todo o dia quer lazer e descanso. Ao dizer que "a televisão é a mais espetacular tradução da industria cultural", a psicanalista e professora da PUC de São Paulo, Maria Rita Kehl, observa:

Diante da TV ligada, isto é, diante de um fluxo contínuo de imagens que nos oferecem o puro gozo, não é necessário pensar. O pensamento é um trabalho e ninguém agüenta pensar (trabalhar) o tempo todo. O pensar só é convocado a operar quando falha a realização de desejos. Então, essa é a primeira premissa: o funcionamento imaginário dispensa o pensamento. Isso não quer dizer que as pessoas parem de pensar para sempre por efeito desse gozo imaginário, mas que, diante do fluxo de imagens, paramos de pensar. E, quanto mais o fluxo de imagens ocupa espaço na nossa vida real e na nossa vida psíquica, menos é convocado o pensamento (KEHL, 2000, p. 136).

Em vez de notícias trágicas ou questões preocupantes, a pessoa quer um resumo superficial do dia para ter assunto com os amigos no dia seguinte. $\mathrm{O}$ professor de Ética e Filosofia Política da Universidade de São Paulo, Renato Janine Ribeiro, aborda a questão:

Como puxar prosa com um desconhecido? Num mundo de grandes cidades, como o nosso, em que é tão comum nos depararmos com gente que nunca vimos antes, que assunto teremos com elas? Qual é o primeiro vínculo que criamos com alguém que é virgem para nós: um vínculo que pode resultar em nada, ou em tudo? E pouco importa se esse vínculo será frágil, durante alguns segundos, ou se vai durar para a vida toda. Porque, ali onde encontramos assunto para falar com o outro, é onde encontramos a matéria-prima do laço social, a base para a res publica possível, para o que possa haver de comum entre nós e os demais (JANINE RIBEIRO, 2005, p. 96).

\section{Prossegue:}

Esse estoque de assuntos s encontra, hoje, sobretudo na televisão. Ela fornece a matéria-prima para o encontro dos desconhecidos - e, na cidade, quase todos os outros são meus desconhecidos. O concidadão é um desconhecido. A cidadania se faz com desconhecidos. Por isso é tão importante a filosofia política pensar a TV: é 
nela que se encontra não o bem comum ideal, não a república imaginária, mas a possível, a real, com seus defeitos, mas também suas potencialidades (JANINE RIBEIRO, 2005, p. 97).

A praça pública onde os gregos se reuniam na antiguidade para discutir a sociedade, hoje é representada pela mídia, com ênfase na televisão por ela representar o meio com maior alcance e visibilidade. O professor de sociologia política da Universidade de Cambridge, na Inglaterra, John Thompson, diz que o uso da mídia não implica apenas na transmissão de informações, mas cria novas formas de ação e interação. E completa:

A mídia transformou as condições da vida social e política. Uma das consequiências foi a transformação da visibilidade. Há algum tempo, um acontecimento público era o que acontecia em locais abertos, acessíveis a todos, e para ser visto era necessária a presença física. Privado era o que permanecia restrito a poucos, atrás de portas fechadas. Com a Mídia, público e privado adquiriram um novo sentido. Público é o que pode ser alcançado pelo olho da grande mídia, ao transmitir um evento a milhões de pessoas, distantes no espaço e afastadas no tempo. Público agora é o visível (THOMPSON, 2000, p. 11).

É indiscutível a influência da TV na formação de opinião por parte do público. Mais do que informar, ela forma conceitos e opiniões. E todos querem ter uma opinião formada sobre os assuntos do dia-adia. Ninguém, do mais culto ao que tem menos formação, quer passar por desinformado ante os fatos que estão em discussão no cotidiano das pessoas. Eugênio Bucci, doutor em Ciências da Comunicação pela Universidade de São Paulo e atual presidente da Radiobrás, diz que "os fatos que contam a história recente são mediados pela televisão". E acrescenta:

A televisão é um organismo. Ela vive como um organismo. Enquanto fabrica e difunde ficção para o consumo, a TV reinstaura o seu lugar no passado afetivo de cada telespectador. À medida que reporta os acontecimentos presentes, renegocia seu lugar dentro do passado factual. Todo o dia reescreve a sua própria história, valendo-se de recursos que mesclam jornalismo e ficção (BUCCI, 2004, p. 205).

\section{Complementa:}

A TV une e iguala, no plano imaginário, um país cuja realidade é constituída de contrastes, conflitos e contradições violentas. A TV conseguiu produzir a unidade imaginária onde só havia contradições violentas (BUCCI, 2004, p. 222).

\section{Vinheta de encerramento: conclusões}

A TV é uma fusão do cinema com o rádio. Usa a linguagem visual adotada no cinema, com a narrativa oral do rádio e o texto da imprensa. Mas, por fazer uma fusão entre imagem e som, parece mais espontânea. Já foi dito que uma imagem vale por mil palavras. Não é bem assim. Mas é preciso alertar que a imagem pode encobrir o que está sendo dito pelo texto, pode esconder palavras que seriam fundamentais, para a perfeita compreensão do assunto. Um exemplo: a pausa na narração de um texto, ao criar o silêncio, por alguns segundos, tem enorme significado. Apenas a imagem, sem narração ou música de fundo, por certo vai atrair a atenção do telespectador para o que está sendo mostrado. É o silêncio que vale muitas palavras, a imagem vai falar por si. E isso em uma tela luminosa, que está sempre em constante movimento, significa muito.

A televisão dá prioridade ao componente visual, de maneira a causar fascinação ao público. Ela aumenta o peso da imagem em relação ao valor da palavra. E o telespectador decodifica, mais facilmente, os códigos visuais do que os verbais. Se alguém diz que "isso apareceu na TV", o outro aceita, passivamente, a situação como um fato real: "Se apareceu na TV, então aconteceu".

Mas ela não é mera observadora dos fatos. Por trás de uma câmera, está o olhar de um cinegrafista. A matéria jornalística é uma história contada pela ótica do repórter, com as imagens captadas pelo cinegrafista. Na edição o jornalista faz escolhas, optando por uma e não por outra cena, por esse e não por aquele trecho da resposta do entrevistado. TV é edição, é recorte, é fragmento. $\mathrm{O}$ desafio de quem trabalha nela é escolher certo, com responsabilidade, critério, ética, e, principalmente, honestidade. Existe imparcialidade jornalística? É claro que não. A ótica do jornalista, do cinegrafista, do fotógrafo, do diretor da empresa e dos interesses que ela representa, sempre estarão de algum lado. Objetividade? Muito menos. É importante registrar um dos editoriais da revista Carta Capital, em plena campanha eleitoral, na edição anterior ao primeiro turno das eleições de 2002:

Objetividade? Objetiva mesmo só a máquina quando funciona. O homem jornalista é subjetivo até no momento de colocar uma vírgula no meio do período. Do profissional de comunicação exige-se honestidade. Na mídia nativa, a alegada busca da imparcialidade e da objetividade serve apenas como adubo da hipocrisia. Tanto mais em tempo de campanha eleitoral. Jornais, revistas, meios de comunicação em geral, apóiam o poder pelo simples fato de que fazem parte dele, são o seu instrumento. Ou, por outra, apóiam a si próprios. Sem qualquer preocupação quanto à honestidade (CARTA, 2002, p. 18). 
As campanhas políticas não dispensam o uso cada vez mais acentuado de recursos eletrônicos e audiovisuais. Os tradicionais comícios, nos palanques das praças nas cidades do interior ou em pontos tradicionais do centro das grandes cidades, raramente, são realizados e, quando ocorrem, é para permitir gravações de imagens e sons, para utilização na propaganda política pelo rádio e TV. Nas campanhas, os candidatos preparam-se muito mais para as aparições no vídeo do que para o contato físico com os eleitores nas ruas.

Os candidatos seguem à risca as orientações de seus consultores de marketing, dando a eles muito mais atenção do que a dispensada aos assessores políticos. O corte dos ternos, a cor das camisas ou a estampa das gravatas, tudo é cuidadosamente escolhido para dar aos candidatos uma aparência mais séria ou informal, de acordo com o que for exigido pela situação. Esses detalhes fundamentais, para a obtenção de bons resultados diante da tela de TV, ajudam a construir a imagem do candidato, para que ele não fique com uma aparência distante do assunto de que está tratando. E o cuidado nos mínimos detalhes não é casual. A Mídia é o espaço, onde a política acontece.

Os meios de comunicação substituíram partidos, sindicatos, intelectuais. A aparição súbita desses meios põe em evidência uma reestruturação geral das articulações entre o público e o privado que pode ser percebida também no novo ordenamento da vida urbana, no declínio das nações como entidades que comportam o social e na reorganização das funções dos atores políticos tradicionais (CANCLINI, 1999, p. 50).

$\mathrm{O}$ autor considera que as campanhas eleitorais migraram dos comícios em palanques para as telas da TV. As questões ideológicas deram lugar ao confronto de imagens: "A esfera pública foi absorvida, substituída pela mídia" (Canclini, 1999, p.58). Para Sartori, na TV, mais do que em qualquer outro Meio de Comunicação, "é o produtor que produz o consumidor". Ele faz referência a uma nova classe, resultante da crescente influência da Mídia na política:

A nova classe que gera o videopoder tenta se defender da acusação, atribuindo culpa às audiências. Sim, mas trata-se de uma defesa de má fé, pois na televisão, mais do que em qualquer outro meio, é o produtor que produz o consumidor (SARTORI, 1999, p. 130).

Por trás de tudo, e também da tela da TV, está a questão ética. Todos nós sabemos que a televisão não pode mostrar tudo. Ela resume ao final do dia os principais fatos, do mundo, do país, do estado, da cidade. Não pode mostrar tudo, mas deve resumir o principal. Seja da china, seja da esquina. Mas o filtro para escolher as melhores notícias e as imagens dessas notícias deve ser a conduta ética do profissional encarregado da seleção, da escolha, da mediação. O jornalista é o medidor que transforma o fato em notícia. E o principal instrumento de trabalho dele não é a caneta, o computador, a câmera ou a ilha de edição. É, isso sim, a conduta ética com a qual vai construir o seu trabalho, no caso o seu telejornal. Observemos, mais uma vez, o que diz Janine Ribeiro:

Devemos discutir os jornais de TV segundo a ética? Pouca gente dirá que não. Mas podemos dizer que eles sejam éticos? É difícil. (...) A questão ética, sobre os noticiários, está na qualidade da cobertura e na diversidade dos pontos de vista. Qualquer estudante de comunicação sabe que não há objetividade pura: que mesmo um retrato privilegia pontos de vista, enfoques, excluindo outros. E no entanto não dá para fazer bom jornalismo sem acreditar que seja possível uma certa objetividade. É uma crença insustentável segundo a boa filosofia, ms imprescindível para fazer uma boa reportagem.

Essa fé impõe obrigações ao jornalista. Ele deve admitir que, mesmo nos casos mais escabrosos, haja um outro lado - o qual deve ter seu lugar na página ou na tela. Deve repelir imagens degradantes ou abjetas. Deve evitar a linguagem indignada. Deve, enfim, desconfiar da unanimidade, que é inimiga da reflexão (JANINE RIBEIRO, 2005, p. 105).

As reflexões acima propostas encaminham para o encerramento do presente artigo. O objetivo deste trabalho foi fazer uma provocação. Nada de Teoria da Conspiração ou das freqüentes tentativas dos parlamentares e governantes (o presidente Lula é o mais recente deles) em culpar a imprensa pelos fracassos de seus projetos políticos. Na verdade, a TV recorta a realidade todos os dias. Mostra muito, mas esconde muito também.

A ideologia embutida na edição dos telejornais é o que determina a superexposição de determinados temas e a ausência absoluta de outros, por certo os que mais interessam ao público em geral.

A TV é uma grande máquina de contar histórias. Não que ela as invente, mas certo que ela as enfeita conforme suas conveniências políticas, ideológicas ou empresariais. Os retratos do mundo que nos são mostrados todos os dias pela TV constituem o mosaico com o qual tomamos conhecimento do que está acontecendo.

E o desafio de quem faz ou de quem estuda televisão é aproximar cada vez mais o mundo da tela luminosa da TV. A lente que fará essa aproximação é a lente da verdade, manejada por um profissional ético e honesto.mpamecos 
Flávio A. C. Porcello • 79-84

\section{REFERÊNCIAS}

BOURDIEU, Pierre. Sobre a televisão. Rio: Jorge Zahar Editor, 1996.

BUCCI, Eugênio \& KEHL, Maria Rita. Videologias. São Paulo: Boitempo Editorial, 2004.

CANCLINI, Nestor Garcia. Consumidores e Cidadãos. Rio: Editora UFRJ, 1999.

CARTA, Mino. "Carta Capital escolhe Lula". Revista Carta Capital, São Paulo, Ano VIII, número 209, 02/10/2002, p.18.

FARINA, Modesto. Psicodinâmica das cores em comunicação. São Paulo: Editora Edgar Blücher, 1990.

KEHL, Maria Rita in HAMBURGUER, Ester \& BUCCI, Eugênio. A TV aos 50. São Paulo: Ed. Fund. Perseu Abramo, 2000.

JANINE RIBEIRO, Renato. O afeto autoritário: televisão, ética e democracia. São Paulo: Ateliê Editorial, 2005.

SARTORI, Giovanni. Homo Videns: Televisão e Póspensamento. Lisboa: Terramar, 1999. Ateliê Editorial, 2005.

THOMPSON, John B. O escândalo político: Poder e visibilidade na era da Mídia. Petrópolis: Editora Vozes, 2000. 